Military Technical College Kobry El-Kobbah, Cairo, Egypt

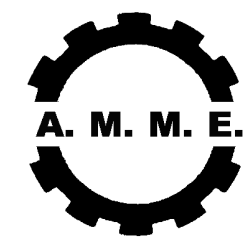

\title{
Investigations of application of composite materials in packing machines
}

$$
\text { By }
$$

Ana Pavlovic , Snezana Ciric Kostic, Cristiano Fragassa, Zlatan Soskic*

\section{Abstract:}

The paper presents analysis of mechanical behaviour of components of packing machines in which steel parts are replaced by parts made of metal matrix composite materials (MMCM). In this purpose, linear analytical and numerical analyses were applied for calculation of stiffness of the parts, and nonlinear numerical analysis of functional behaviour of the components was performed. Besides, flexible dynamic analysis was applied for consideration of impact behaviour. The results show that, while masses of the parts are reduced around $25 \%$, desired adhesive properties and impact resistance are achieved.

Keywords: Packing machines, Metal Matrix Composite Materials, ANSYS WB, non linearity, flexible dynamic analysis

\section{Introduction:}

In the 1980's a small artisan company starts to produces robot for packaging, equipped with rechargeable batteries and a feeler, which turned autonomously around pallets of any size, applying stretch film to stabilize the load. This innovative idea was later patented and widespread all over the world. Soon the company became well known as a world leader in semi-automatic machines for the application of stretch film for stabilizing pallet loads, developing a number of other machines to join the robot including: rotating tables, horizontal wrapping machines for elongated products, a ranges of shrink film packaging machines and taping machines. These automatic systems and

* Faculty of Mechanical Enginering-Kraljevo, University of Kragujevac, Serbia 
machines are able to stabilize pallet loads with stretch film capable of catering for up to 100 pallets per hour, thanks to a range of high-tech solutions with excellent levels of productivity.

The commercial success for every packaging machine is directly related to a correct balance between costs of equipments (as low as we can) and efficiency in processes (as high as it is possible). Regarding this second aspect, during the last years, the sector noticed a progression of technical solutions toward faster and faster machines. From an engineering point of view, one of the simplest ways to speed up a machine is to take particular care to reduce inertial masses. This result can be obtaining modifying geometry or changing the material.

This study is focused on the optimisation of a pretension spooler for the stretching of elastic film and film spool supports. The pretension spooler together with it's support are fundamental components inside the semi-automatic packaging machine permitting, coupled with other spoolers, to accurately calibrate the ratio of stretching for the elastic film (reducing wastes of film), but also the wrapping up pressure on the pack (assuring the stability of pallet and the integrity of goods during the packaging process). Linear and non linear FEM analyses were used together with a theoretical modelling of physical conditions for the pretension spooler. The hypothesis to substitute steel with aluminium was considered and accepted. A reduction in thinness and new solutions to guarantee the same level of friction on surface were taken in count.

Besides, modal analysis and flexible dynamic analysis were applied to film spool supports. The case when film spool cylinder crash on the three supports (due to fall) is considered by FEM analysis.

\section{Components inside machines:}

The study is focused on a vertical stretch wrapping machine (fig.1). In this configuration the pretension spooler represents an important and critical component for the packaging machine, with a strong impact on the entire system. Assembled on a mobile unit, every problem to the pretension spooler can provoke an unstable working condition for the machine.

The machine contains two spoolers (fig. 2) which, revolving with two different angular velocities, create the stretching forces on the film. In this way an elastic-plastic deformation of $300 \%$ is realized on the film. By this extension, it is possible to reach several results:

- a minor length of film is used for packaging the pallet reducing costs, but also limiting wastes of materials with a beneficial impact on the environmental aspects of the process;

- a proper level of pressure and compressive forces on the pallet is created, able to stabilize it permitting a safer transportation and a protected storing. 

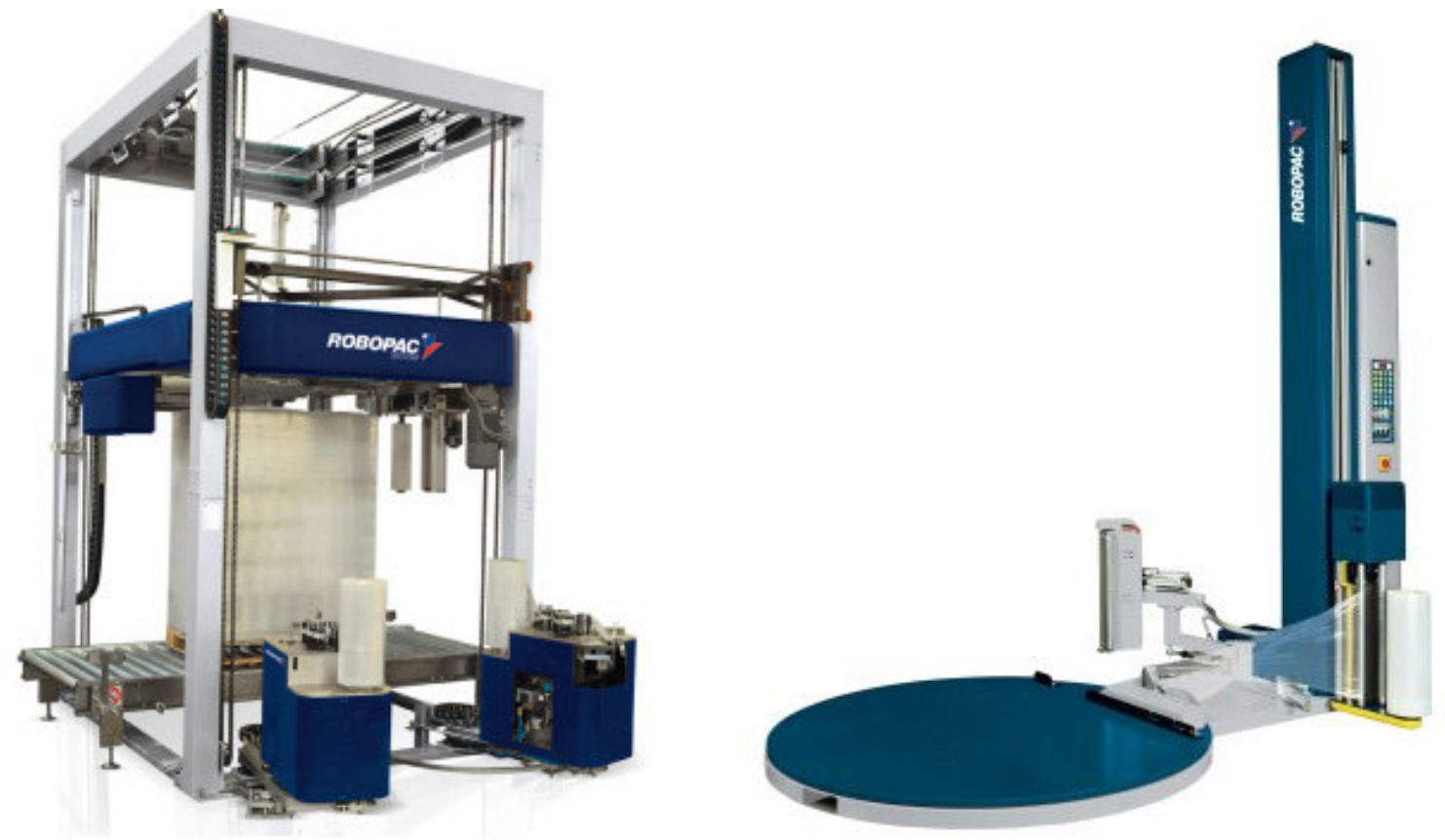

Figure (1): Some types of vertical stretch wrapping machines

The pretension spooler is realized by steel metal sheets, with a thickness of $3 \mathrm{~mm}$ able to assure an appropriate stiffness. A layer of vulcanized rubber is deposed on surface to obtain a friction able to drag and stretch the film.

Spooler's weight becomes relevant, especially in transient conditions and provokes an over-dimensioning of the whole frame with inefficiency in the dynamic of the machine.
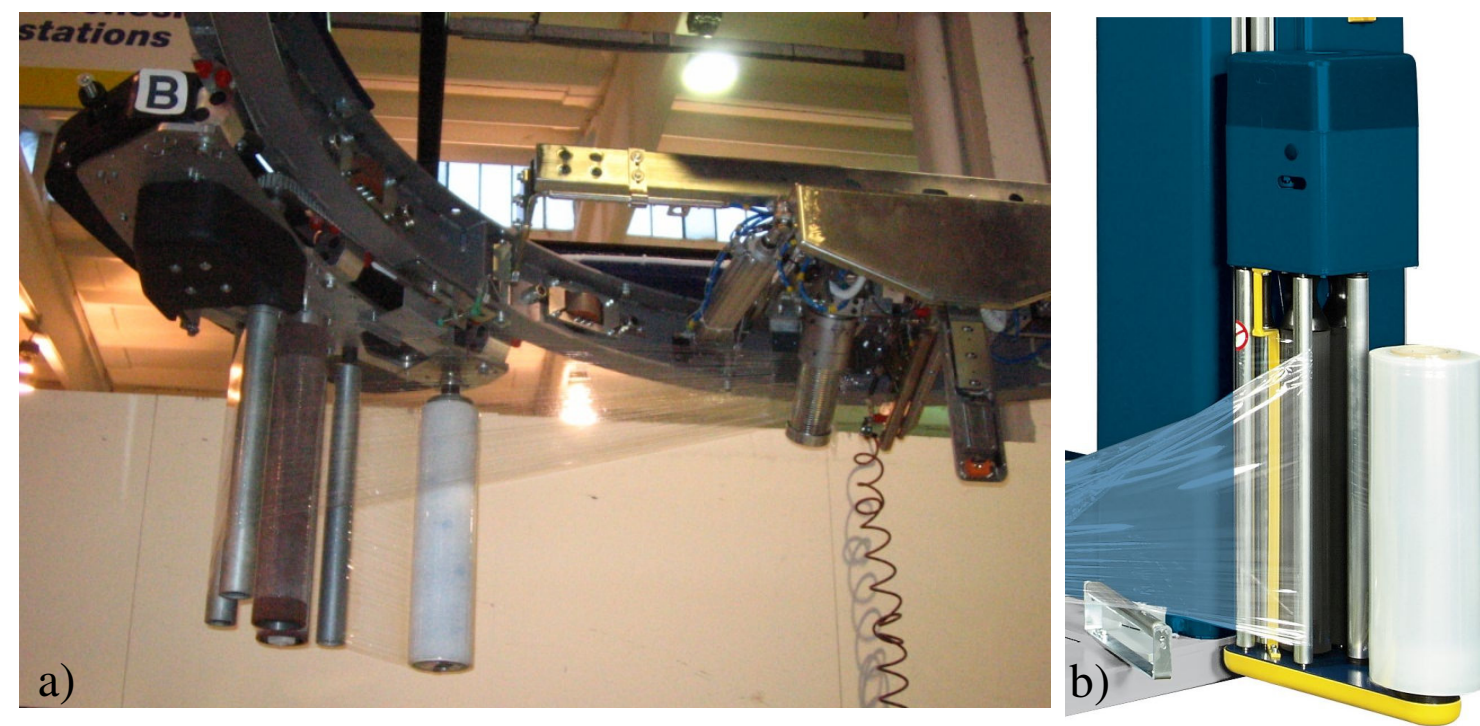

Figure (2): Systems of pretension spoolers and film spool 
The second review component is film spool supports. The film spool has initial weight of $20 \mathrm{~kg}$ and leans on three film spool supports that form angles of 120 degrees between them and are linked to the frame by complex hinges. The film spool supports are exposed to wear due to the rotation of the film spool around its axis. Since high explosion on the wearing of material, therefore, they are being replaced whenever film spool is changed. The potential solution could be replacing of steel parts by novel materials with improved properties. This paper considers application of Metal Matrix Composite Materials (MMCM) for the purpose.

\section{A hipothesis of use of new materials:}

A reduction in weigh can be obtained using lighter materials (as aluminum or others). In DIEM - University of Bologna, several MMCMs are under investigation for their high mechanical performances, especially the family of composite materials with aluminum matrix and ceramic inserts for their lightening and high resistance to wearing. MMCMs also present several disadvantages as high ductility, high toughness and difficulty in working with normal burr cutter.

Anyway, MMCMs already represent a valid engineering solution in several industrial applications, but, since the high costs for production and manufacturing (for example, they need specific tools and advanced tool machines), at the current state, their diffusion is limited to few borderline applications, especially in transportation (as brakes in high-speed trains).

Our progress beyond the state-of-art is related to the research idea to use a different process for production of MMCMs. At the Laboratory for Innovative Materials in Mechanical Design (MATMEC) of the University of Bologna, a metal casting process involving MMCMs has been established in its fundamental parts. Some prototypal casts in MMCM are now available and the use of MMCM for ordinary industrial applications represents the next challenge.

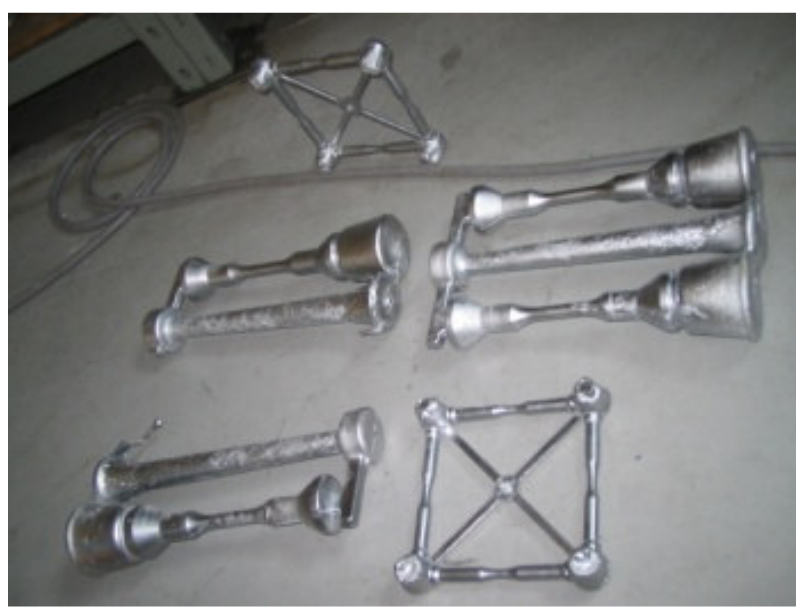

Figure (3): Metal casting of MMCMs 
This paper proposes a first conceptual application of MMCM to the case of a packaging machine. Passing by theoretical and FEM validation, we propose a change in materials for a fundamental part of the automatic plant. In some aspect of calculation, MMCMs' mechanical behavior are approximate with aluminum's parameters since the main differences are related to friction coefficient and wearing progression.

\section{Concepts of design review:}

Substituting steel $\left(7.8 \mathrm{~kg} / \mathrm{dm}^{3}\right)$ with a lower density material, as MMCM or also aluminum $\left(2.8 \mathrm{~kg} / \mathrm{dm}^{3}\right)$ is going to offer lighter components and a better dynamic response of machine. But, at the same time, it is necessary to take in count of the differences in the mechanical resistance for materials (the yield stress for aluminum is $130 \mathrm{MPa}$ much less than 200-400 MPa for steel).

Then, instead of a simple change of constructive material, a significant reduction of weight can be achieved through proper modifications of the geometry and, if possible, the principles of functioning for components, so as to make use of the most of the properties of MMCMs. Specifically:

1. Providing the new design solutions are able to assure a suitable stiffness, the pretension spooler can be also realized with a reduction in thickness. Considering designers so far have not been determining optimal stiffness for the correct functionality of this component (instead of trying to increase stiffness to maximum possible extent), an exact calculation of deformation under load may reveal a possibility to reduce thickness and weight;

2. Providing the contact surface made of MMCMs is able to assure a proper friction coefficient to drag and deform the film in the right way, it is possible to avoid the additional layer of vulcanized rubber (thus reducing costs) on film spool. It would in the same time solve present problem of rubber wear.

3. Providing that film spool supports do not show plastic deformation under the impact forces caused by fall of the film spool, they could be also made of MCMMs, with potential to have smaller wear then steel counterparts, being that MCMM have shown increased surface layer's hardness and increased resistance to wearing respect to steel. Replacement of steel by MMCM would also lead to reduction of the mass of the part, but it would not be of any practical importance for operation of the machine, being that the part has small dimensions and mass.

\section{Theoretical approach:}

The behavior of the structure under working conditions were firstly investigated with a theoretical approach by the following steps:

For a theoretical analysis of pretension spooler, the system could be represented by a 
clamped beam (fig. 4). Boundary and load conditions for spooler could be simplified considering a fixed boundary on the supporting surface and an equally distributed load on a segment of the beam (corresponding with the contact area for the film). Some of important facts of evaluation of forces and loads are shown in fig 4. Complete analytical evaluation of pretension spooler was realized. This procedure is described in [4].

a)

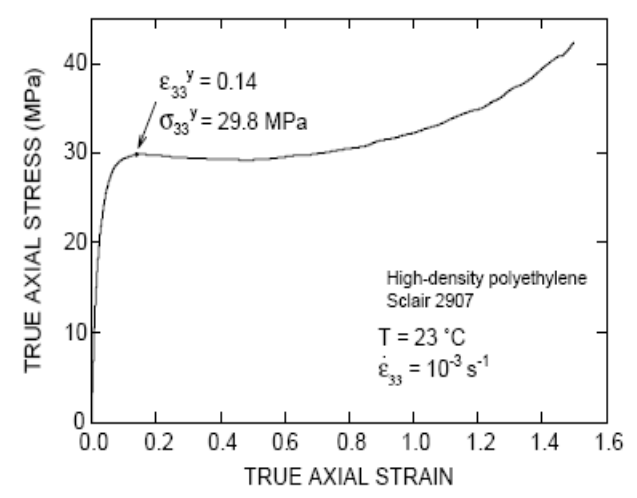

c)

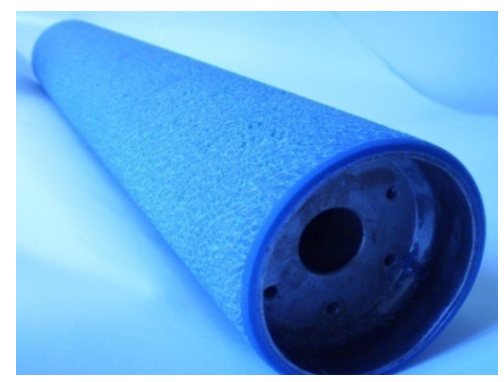

b)

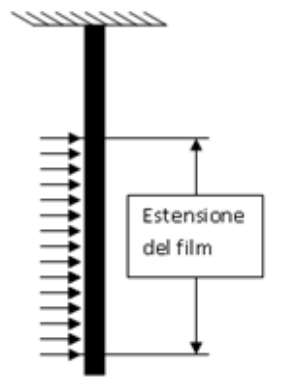

\begin{tabular}{|c|c|c|c|c|c|c|c|}
\hline \multirow{2}{*}{ Density } & & \multirow[b]{2}{*}{$\mathrm{Kg} / \mathrm{mc}$} & \multicolumn{3}{|c|}{ Steel and rubber } & \multicolumn{2}{|c|}{$\begin{array}{c}\text { MCMM } \\
\text { (aluminium) }\end{array}$} \\
\hline & & & \multicolumn{2}{|c|}{$7^{\prime} 850$} & 720 & \multicolumn{2}{|c|}{$2^{\prime} 770$} \\
\hline \multicolumn{2}{|c|}{ Moment of Inertia } & $M m_{4}$ & \multicolumn{2}{|c|}{$530^{\prime} 000$} & $930^{\prime} 000$ & \multicolumn{2}{|c|}{$1^{\prime} 500^{\prime} 000$} \\
\hline \multicolumn{2}{|l|}{ Yield stress } & $M P a$ & \multicolumn{2}{|c|}{$900-1^{\prime} 200$} & & \multicolumn{2}{|c|}{$100-120$} \\
\hline \multicolumn{2}{|l|}{ Thickness } & $\mathrm{mm}$ & \multicolumn{2}{|l|}{6} & 8 & \multicolumn{2}{|c|}{14} \\
\hline \multicolumn{2}{|c|}{$\begin{array}{l}\text { Film pressure } \\
\text { (polyethylene) }\end{array}$} & N & 500 & & & 500 & \\
\hline \multicolumn{2}{|c|}{ Weight of roller } & $\mathrm{Kg}$ & & 3.2 & & & 2.5 \\
\hline & Mflexure & $\mathrm{Nm}$ & 123 & & & 123 & \\
\hline & Mtorion & $\mathrm{Nm}$ & 20 & & & 22 & \\
\hline & $\sigma_{\max }$ & Mpa & 3.6 & & & 3.7 & \\
\hline & $\eta_{\max }$ & $M m$ & 0.06 & & & 0.07 & \\
\hline
\end{tabular}

Figure (4): a) The pretension spooler, b) Model of cantilevered beam, c) Tensile behaviour of the polyethylene, d) Main parameters and results for the analytical evaluations
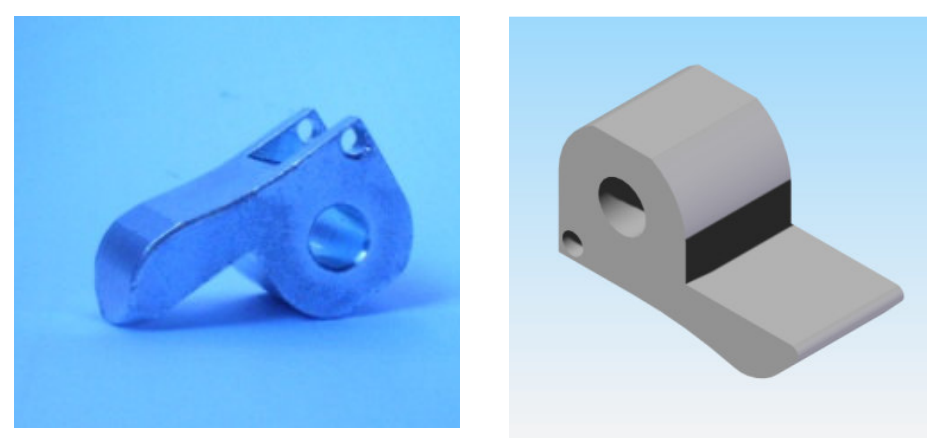

Figure (5): Film spool support 


\section{Using finite elements method:}

Numerical Simulations are concluded by "Smart Engineering Solver" of Ansys Workbench R.12 (fig. 6).
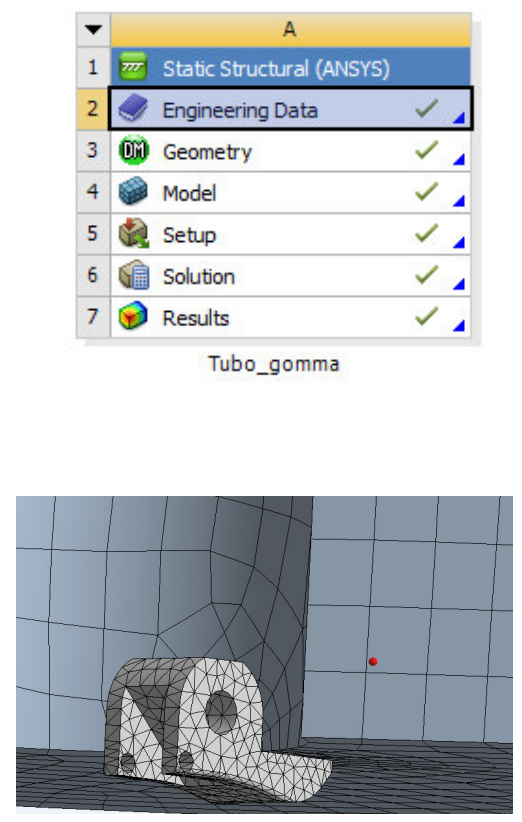
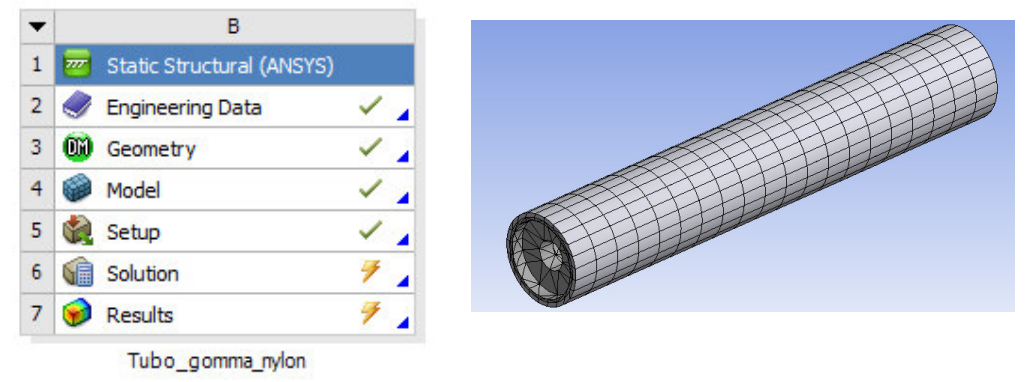

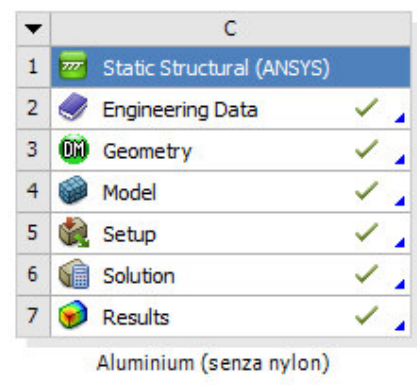

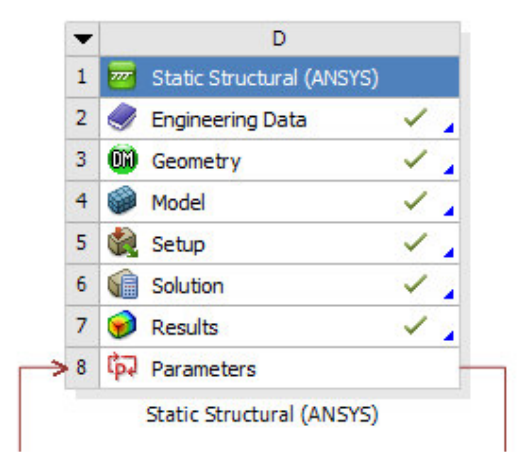

Figure (6): Mesh of both components and New Ansys WB approach of analysis

Static linear and nonlinear analyses were performed in the case of film spooler to determinate stiffness of the components and adhesive properties between spooler and film. Linear analyses were done in all case of steel, aluminium and MMCM materials. Two nonlinear analyses were performed for contact problems between the spooler and film, first in the case of contact between of steel-rubber and polyethylene and second between MMCM and polyethylene. In the case of film spooler support, the flexible dynamic analyses were performed to obtain impact resistance of the structure. These analyses consider the crash problem of $20 \mathrm{~kg}$ weight spooler that is falling down on the much smaller support. Since three supports are not connected between each other, it was performed impact analysis only between one support and the third part of the spooler.

Geometries of both components were designed in CAD environment of Solid Edge (fig.5), geometry was exported to Ansys WB. Volumes were discretized by finite elements. As material characteristics steel, rubber or aluminum were inserted according to each specific simulation for comparison. Several conditions for loads and boundaries were investigated. Von Mises stresses and relative deformations were observed highlighting the critical zones. 


\section{Results and discussion of models:}

In the case of a pretension spooler made by "solid" MMCM (or aluminum) material, simulations calculation could be performed without particular difficulties since the problem is linear. FEM results were compared with analytical estimations in several cases under investigation.

On the opposite, for the "old" spooler, made by a "sandwich" of materials, a non linearity occurs.

In general, non linear analysis is requests if the model presents nonlinearity in:

- the geometry, as in the case of large displacements, angles, deformations or their combinations;

- the behavior of materials. Rubber and hyper-elastic materials (as polyethylene) are typical examples of non linearity in materials. A non linear behavior is related to some unusual aspects as the fact that the relation between stress and deformation depends on the number of cycles of loads, on the speed of application of loads and, even, on the temperature;

- the contact when boundary conditions change since the application of loads.

During our simulations, the models were subjected not only to nonlinearity in materials (polyethylene and vulcanized rubber), but also nonlinearity in contact (between rubber and steel) with changes of contact areas under the pressure of film, and even non linearity of geometry like large displacement in the film. Regarding the large distortion of polyethylene, plastic deformation of materials has to be treated with particular attention.
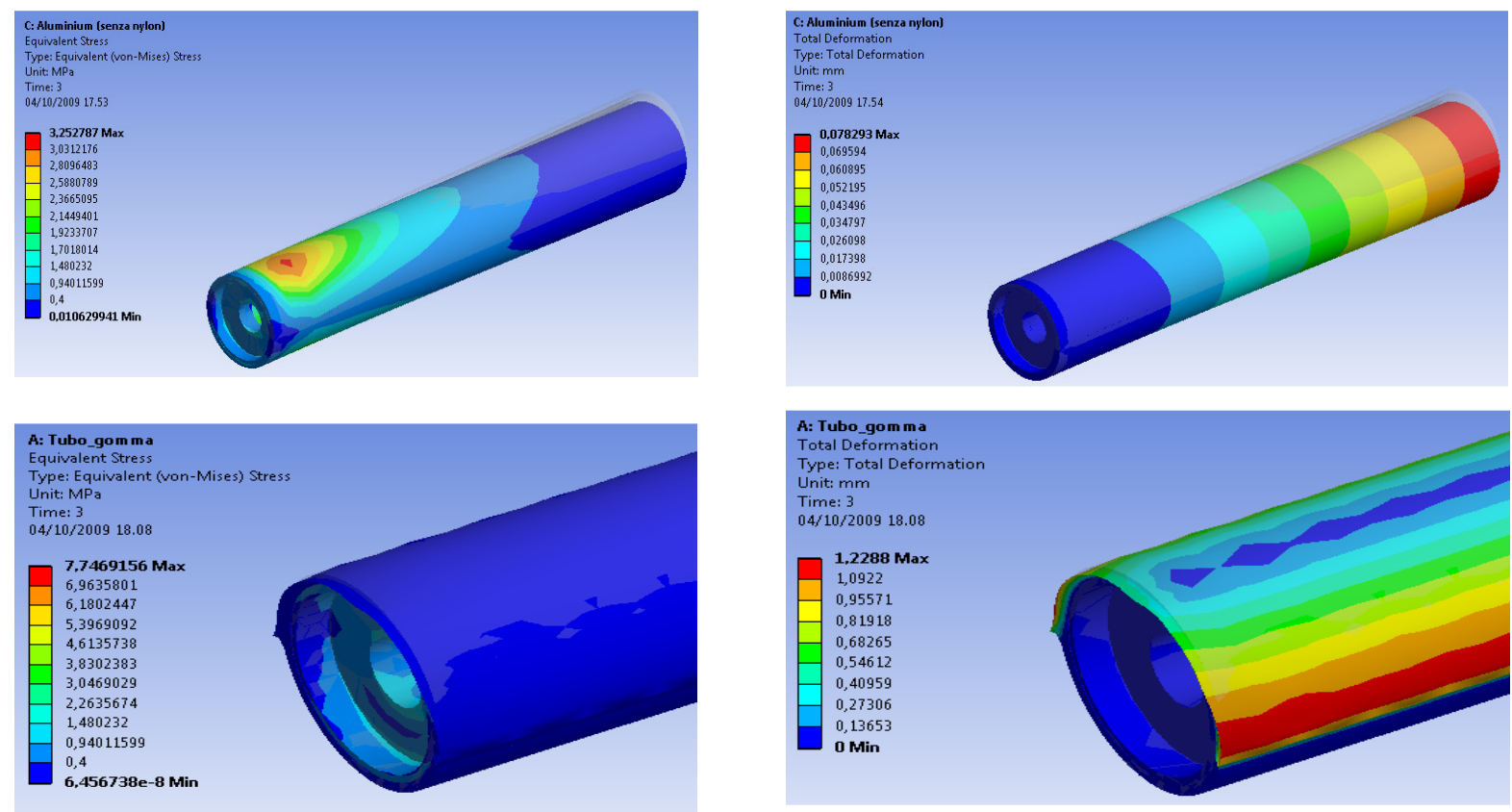

Figure (7): Stress and strain distribution: a) MMCM spooler, b) "sandwich" of steel and rubber under the pressure of film 
a)

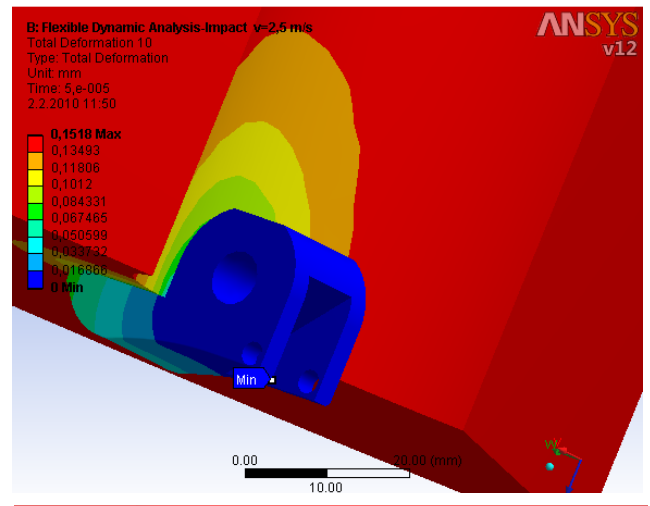

b)

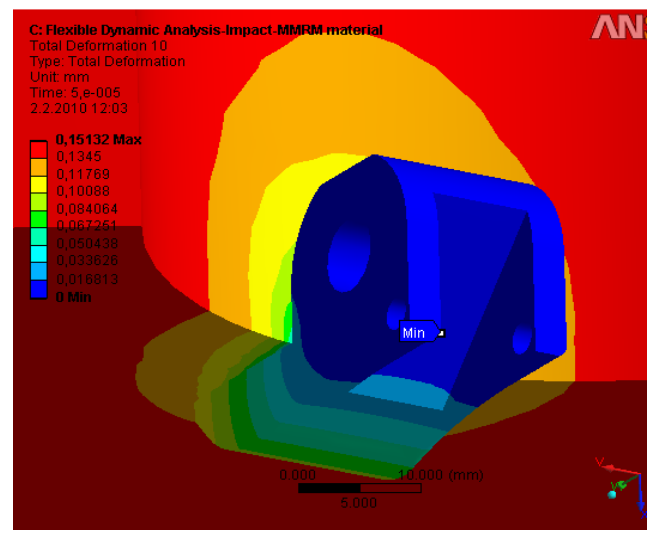

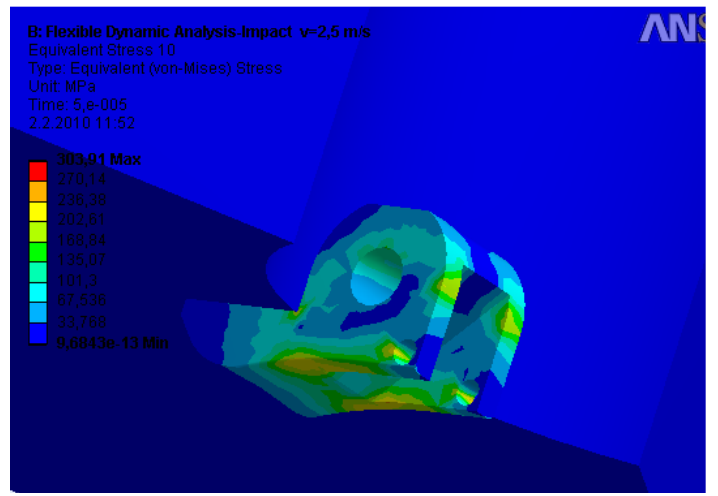

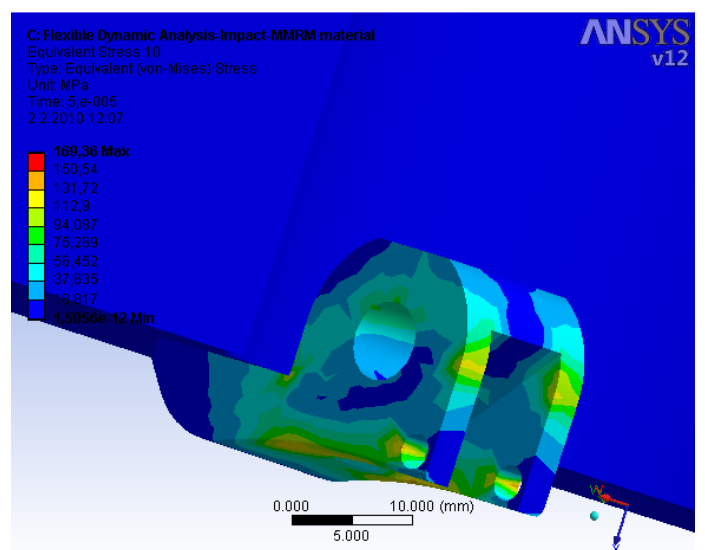

Figure (8): Stress and strain distribution: a) steel film spool support,b) MMCM film spool support

In this case, it was necessary to choose with care the type of contact for each contact surface; the contact between steel and rubber was defined as "bonded". Moreover exact stress- strain curve for non linear material as rubber and polyethylene were inserted as input. Large displacements were taken in consideration activating the solver for "large deflection" in a time-consuming process. Some results as stress and strain distributions are reported (fig. 7, fig. 8) and they are according with all the analytical evaluations.

Flexible dynamic analysis encompasses static structural analysis and rigid dynamic analysis, and it allows for all types of connection, loads and supports. In this paper it was represent the impact of the cylinder on the film spool support with the velocity of $3 \mathrm{~m} / \mathrm{s}$. However one of the important considerations of performing this analysis is the time step size. The general suggestion for selection of the initial time step size is to use the following equation:

$$
\Delta t_{\text {initial }}=\frac{1}{20 f_{\text {response }}}
$$

Where $f_{\text {response }}$ is the frequency of the highest mod of interest. In order to determinate the highest mode of interest, a preliminary modal analysis should be performed prior to the flexible dynamic analysis. Performed flexible dynamic analysis involve large deflection 
effects, contact and plasticity hence it is nonlinear. Numerical analysis was performed for two different type of materials of film spool support, steel and MMCM (fig. 8). Obtained results of stress distribution demonstrate that there is no risk of failure in both cases. Equivalent stress and strain are under the critical limits of mentioned materials. MMCM material in the family of composite materials with aluminum matrix and ceramic inserts, for their lightening and high resistance to wearing, can be used in application for packaging machines.

\section{References:}

[1]. T.W. Clyne, An introduction to metal matrix composites, Cambridge Press, 1993.

[2]. ANSYS, User's manual (version 11 and 12), ANSYS Inc., 2009.

[3]. Composite Materials Handbook, Volume 4. Metal Matrix Composites. MILHDBK-17-4. Sept. 1999.

[4]. A.Pavlovic, S. CiricKostic: Design and optimisation of mechanical solutions for high speed components in packing machines, Mehanika Transport Komunikacija, issue 3, art. N.0461, pp. IX-44-IX-47, 2009.

[5]. M. Taya, R.J. Arsenault, Metal Matrix Composites, Thermomechanical behaviour, Pergamon Press, 1989.

[6]. J.W. Kaczmar, K. Pietrzak, W. Wlosinski, The production and application of metal matrix composite materials, Jo. Mat. Proc. Techn. 2000.

[7]. M.D.Huda, M.S.J. Hasmi, M.A. El-Baradie, MMCs, Materials, Manufacturing and Mechanical Properties, Key Eng. Mat., 1995.

[8]. J.Eliasson, R. Sandstrom, Applications of Al Matrix Composites, Key Eng. Mat., 1995.

[9]. M.Kojic, R. Slavkovic, M. Zivkovic, N. Grujovic, Finite element method nonlinear analysis, Faculty of mechanical Engineering in Kragujevac, University of Kragujevac, Kragujevac, SCG, 1998.

[10]. F.Addiegio, A.Dahoun, C.G'Sell, J.M.Hiver, Characterization of volume strain at large deformation under uniaxial tension in high-density polyethylene, Science Direct, May 2006. 